\title{
Prevalence of Work Related Low Back Pain among Physical Therapists with Different Foot Postures at Fayoum, Egypt: A Survey Study
}

\author{
HOSSAM EL-DIN A. IBRAHIM, M.Sc.*; SALWA F. ABD EL-MEGED, Ph.D.**; \\ EBTESSAM F. GOMAA, Ph.D.** and ALAA EL-MARAKBY, M.D.*** \\ The Department of Orthopedic Physical Therapy, Fayoum General Hospital, Fayoum*, \\ The Department of Physical Therapy for Orthopedics, Faculty of Physical Therapy, Cairo University** and \\ Department of Orthopedic Surgery, Fayoum GeneralHospital***, Egypt
}

\begin{abstract}
Background: Low Back Pain (LBP) is the commonest form of musculoskeletal disorder among physical therapists. Repetitive tasks, high force manual techniques bending/twisting postures, patient transfer assisting with mat activities, lifting heavy equipment, prolonged constrained posture and foot abnormalties identified as risk factors of low back pain which is common in the field of physical therapy.
\end{abstract}

Aim of the Study: The purpose of this study was to identify prevalence of work related LBP among physical therapists with different foot postures working in governmental hospitals in fayoum-Egypt.

Subjects and Methods: 147 physical therapists who are working in the governmental hospitals in Fayoum-Egypt, the LBP will be measured by Nordic Questionnaires (NQ) and foot postures measured by Foot Posture Index (FPI).

Results: 112 of the 147P. Ts (76.19\%) have completed the questionnaire. WRLBP $(\mathrm{n}=68)$, non $\operatorname{WRLBP}(\mathrm{n}=25)$, no $\operatorname{LBP}(\mathrm{n}=19)$. The lifetime prevalence of WRLBP was $60.71 \%$, the twelve-month prevalence of WRLBP was $52.67 \%$, the point prevalence of WRLBP was $47.32 \%$, concerning BMI and WRLBP $74.28 \%$ of subjects with BMI of $20-24.9 \mathrm{~kg} / \mathrm{m} 2$ and $54.54 \%$ of subjects with BMI of $25-29.9 \mathrm{~kg} / \mathrm{m} 2$, the WRLBP was present in $54.83 \%$ of female subjects and in $68 \%$ of male subjects, the WRLBP was present in $56 \%$ of subjects with normal foot posture, $55 \%$ of subjects with pronated foot posture, $91 \%$ of subjects with highly pronated foot posture, $100 \%$ of subjects with supinated foot posture and $67 \%$ of subjects with highly supinated foot posture.

Conclusion: There was no statistically significant association between LBP and foot postures, however there was a statistically significant association between WRLBP and BMI. There was a high prevalence of WRLBP among physical therapists who working in governmental hospitals in FayoumEgypt.

Correspondence to: Dr. Hossam El-Din A. Ibrahim, The Department of Orthopedic Physical Therapy, Fayoum General Hospital, Fayoum, Egypt
Key Words: Prevalence - Work related low back pain - Foot postures - Physical therapists.

\section{Introduction}

MECHANICAL low back pain is the most common cause of disability in adults less than the age of 45 and second to arthritis between the ages of 45-65 years [1]. At least $85 \%$ of people will suffer from low back pain at some point during their lifetime [2]. The peak prevalence of low back pain occurs between the ages of 45 to 60 years [1-3] The indirect and direct costs of low back pain are high, including insurance costs and loss of production [2]

Physical therapists are among health professionals who show more postural disturbances since their occupation demands great efforts of the musculoskeletal system, repetitive movements of the upper limbs, maintenance of static and dynamic postures for long periods of time and especially movements which overload the spine [4]

Although back and feet seem like isolated regions of the body they are functionally interconnected through the lower extremity kinematic chain $[5,6]$. Structural and postural abnormalities in the feet are believed to be associated with mechanical LBP due to their ability to cause disturbance of normal muscle and joint biomechanics in the lower back thereby creating stress and strain of lumbopelvic joints leading to LBP $[7,8]$

Foot function has been suggested to be an aetiological mechanism for the development of LBP [8,9]. Although the normal foot effectively transitions between pronation and supination to 
optimize adaptability versus stability as needed, foot malalignments that negatively affect foot mobility may diminish the ability of the lower leg to function optimally during weight-bearing stance [10].

The posture of the feet in standing may have influence on pelvic alignment $[6,11]$ and, consequently, on the spine posture [12-14]. An excessively supinated foot, characterized by a high arch and hypomobile midfoot, may not adequately adapt to the underlying surface, increasing the demand on the surrounding musculoskeletal structures to maintain postural stability and balance [15]. Further, it has been suggested that the cavus foot has less plantar sensory information to rely on than the normal or pronated foot [16]. Conversely, excessive pronation is characterized by a flattening of the medial arch and a hypermobile midfoot but may also place greater demands on the neuromuscular system to stabilize the foot and maintain upright stance $[\mathbf{1 7 , 1 8}]$. The lumbar spine posture depends on the pelvic alignment in standing position [13] Purpose of the study to identify prevalence of work related LBP among physical therapists with different foot postures working in governmental hospitals in Fayoum-Egypt.

\section{Subjects and Methods}

Subjects:

This study was aiming to find out the prevalence of work related low back pain among different foot postures of physical therapists in governmental hospitals at Fayoum-Egypt. Duration of this study was eight months extended from August 2017 to March 2018. LBP has been evaluated by Nordic Questionnaires (NQ) and foot postures was measured by Foot Posture Index (FPI). Inclusion criteria were male and female physical therapists who are working in governmental hospitals in FayoumEgypt since one year at least, their age ranged from (25-60 years) and BMI (20-29.9). Exclusion criteria were fixed foot deformities, back or lower limbs surgeries, and obese subjects (BMI >30).

This study was conducted at the General Fayoum Hospital, Senoris Hospital, Itsa Hospital, Abshway Hospital, Fedimine Hospital, Fever Hospital, Tamya Hospital and Chest Hospital Fayoum, Egypt.

\section{Procedures:}

A- Nordic questionnaire (Appendix 1):

Through a personal visit of the researcher to the governmental hospitals the questionnaire was delivered personally to the physical therapists, the researcher explained the aim of the study to the physical therapists then the questionnaires was collected upon answering completion while a consent was provided as part of the questionnaire as an approval of using data provided by the questionnaire for scientific publication.

If all physical therapists in the hospital didn't answer the questionnaire a follow-up visit one week after the first visit was commenced to make sure all physical therapists have the questionnaire and collect newly answered questionnaires.

If all physical therapists in the hospital didn't fill the questionnaire after the follow-up visit a third confirmatory visit was commenced one week after the second visit to make sure all physical therapists have the questionnaire, answer any questions or clarification on the study and collect newly answered questionnaires.

After the third visit, physical therapists who refused to answer their questionnaire or didn't answer their questionnaire were considered uncooperative and were excluded from the study.

\section{B- Foot Posture Index (FPI) (Appendix 2):}

Every subject was asked to stand in his relaxed stance position with double limb support, the subject was instructed to stand still, with his arm by the side and looking straight ahead, it may be helpful to ask him to take several steps, marching on the spot, prior to setting into a comfortable stance position, during the assessment, it's important to ensure that the subject doesn't swivel to try to see what is happening for himself as this will significantly affect the foot posture, the subject needed to stand still for approximately 2 minutes in total to conduct the assessment, complete uninterrupted access to posterior aspect of the leg and foot was insured [19].

\section{The six clinical criteria employed in FPI were:}

1- Talar head palpation: The only scoring criterion that relies on palpation rather than observation. The head of the talus is palpated on the medial and lateral side of the anterior aspect of the ankle Fig. (1) [19]

2- Supra and infra lateral malleolar curvature:In the neutral foot it has been suggested that the curves should be approximately equal. In the pronated foot the curve bellow the malleolus will be more acute than the curve above due to the abduction of the foot and eversion of the calcaneus. The opposite is true in the supinated foot Fig. (2) [19]. 
3- Calcaneal frontal plane position: The patient standing in the relaxed stance position, the posterior aspect of calcaneus is visualized with the therapist in line with the long axis of the foot Fig. (3) [19].

4- Bulging in the region of the Talo-Navicular Joint (TNJ): In the neutral foot, the area of skin immediately superficial to TNJ will be flat. The TNJ becomes more prominent if the head of talus is adducted in rearfoot pronation. Bulging in this area is thus associated with a pronating foot. In the supinated foot this area may be indented Fig. (4) [19].

5- Height and congruence of the medial longitudinal arch: In a neutral foot, the curvature of the arch should be relatively uniform, similar to a segment of the circumference of a circle. When a foot is supinated the curve of the MLA becomes more acute at the posterior end of the arch. In the excessively pronated foot the MLA becomes flattened in the center Fig. (5) [19].
6- Abduction/adduction of the forefoot on the rearfoot (too many toes sign): When viewed from directly behind, and in line with the long axis of the heel, the neutral foot will allow the therapist to see the forefoot equally on the medial and lateral sides. In the supinated foot the forefoot will adduct on the rearfoot resulting more of the forefoot being visible on the medial side. Conversely pronation of the foot causes the forefoot to abduct resulting in more of the forefoot being visible on the lateral side Fig. (6) [19].

Total FPI score is a whole number between $12,+12$ which categorize patients into 3 groups (neutral, pronated and supinated) feet as follows:

Reference values:

- Normal $=0$ to +5 .

- Pronated $=+6$ to +9 , highly pronated $10+$.

- Supinated $=-1$ to -4 , highly supinated -5 to -12 [19].

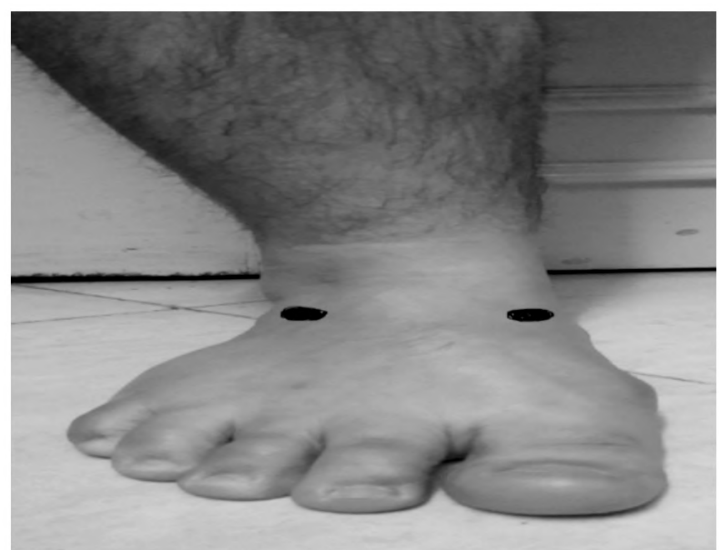

Fig. (1): The position of finger when palpating the head of talus, the circle indicates precise point of palpation on the medial and lateral side.

Supinated $(-1)$

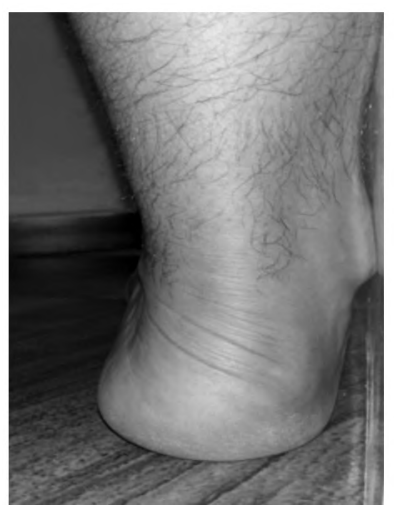

Neutral (0)

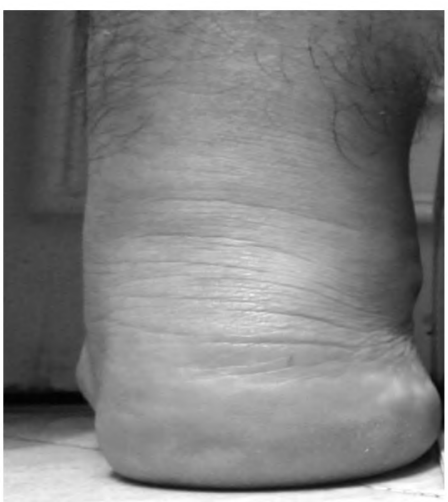

Pronated $(+2)$

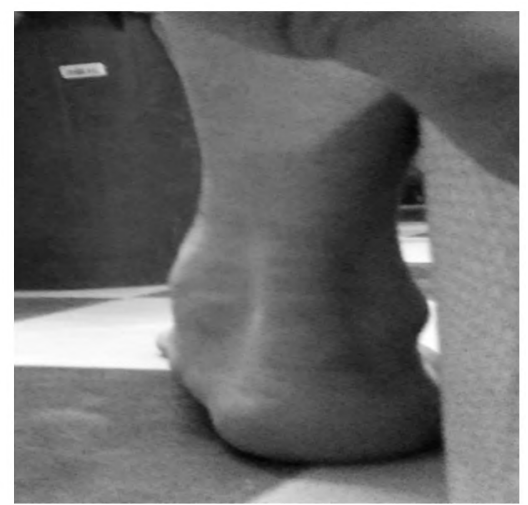

Fig. (2): Supra and infra lateral malleolar curvature. 

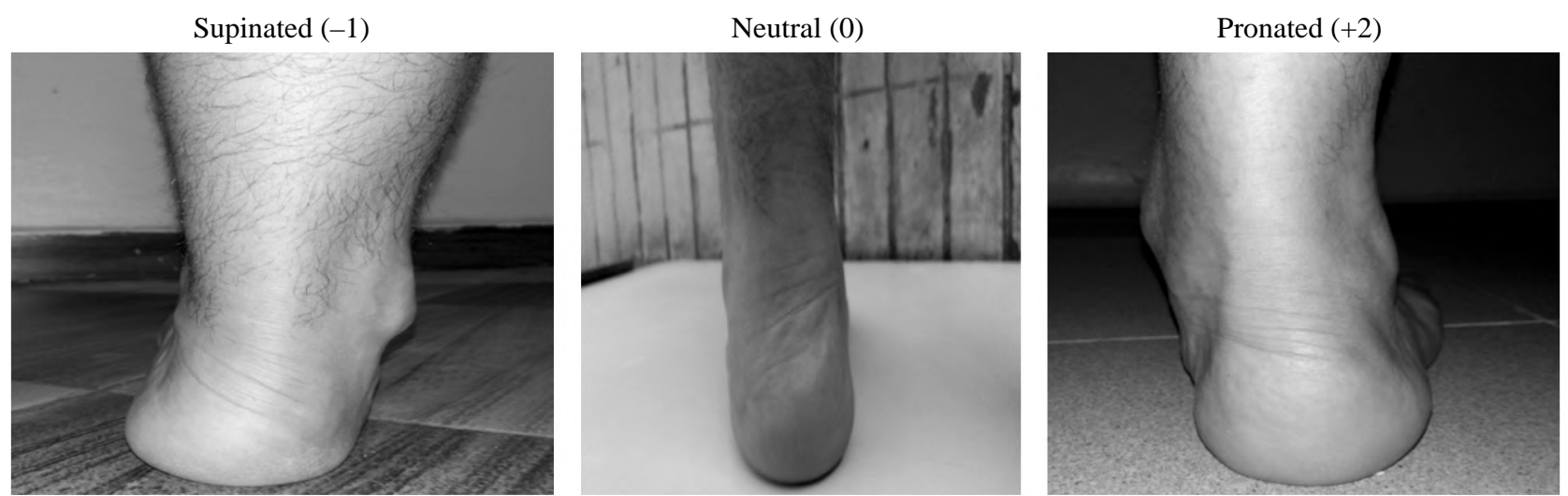

Fig. (3): Calcaneal frontal plane position.
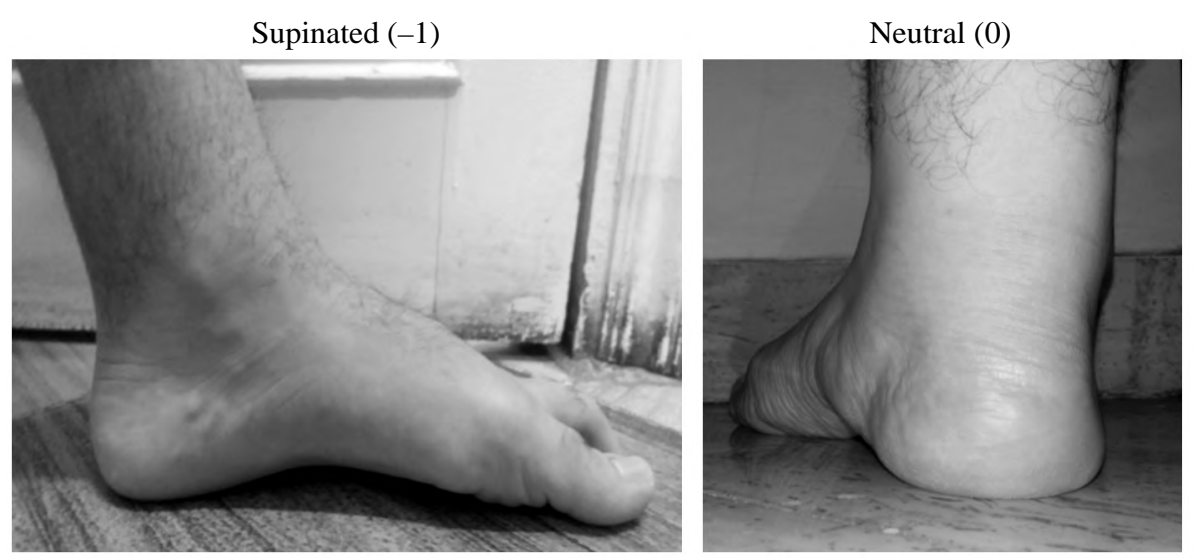

Pronated (+2)

Fig. (4): Bulging in the region of the talo-navicular joint.

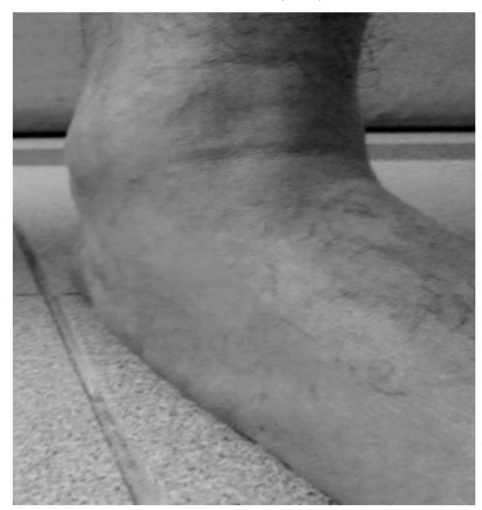

Supinated (-1)

Neutral (0)

Pronated $(+2)$
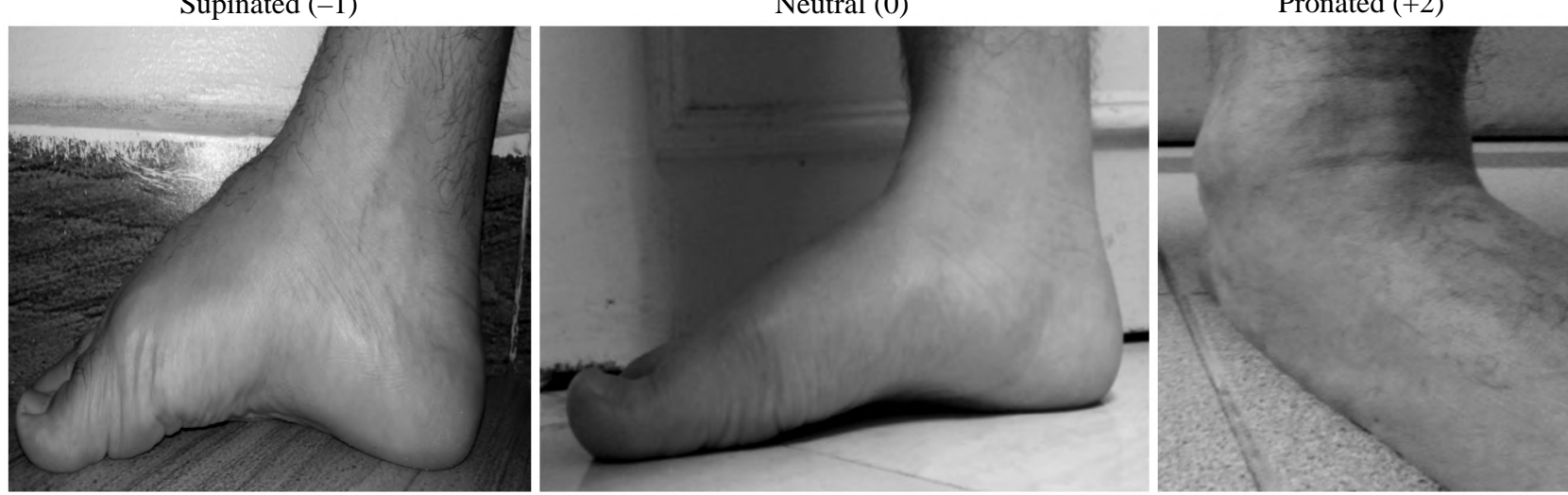

Fig. (5): Height and congruence of the medial longitudinal arch.
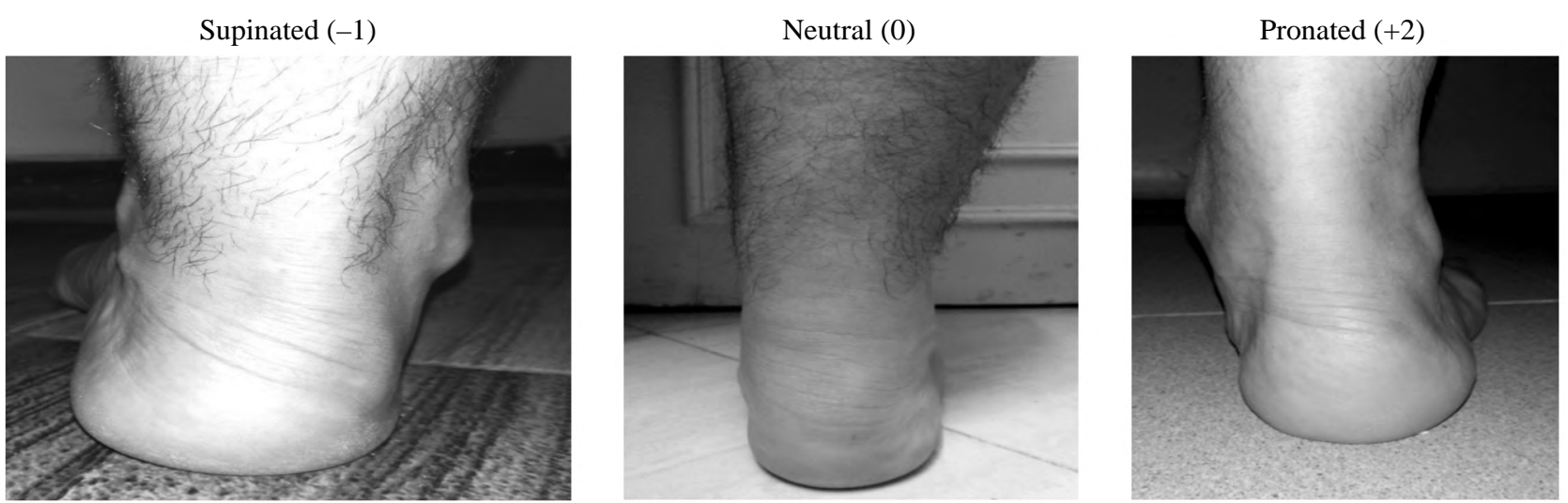

Fig. (6): Abduction/adduction of the forefoot on the rearfoot. 


\section{Results}

Descriptive statistics of mean, standard deviation, frequencies, percentages and Confidence Interval (CI) were utilized in presenting the subjects demographic and LBP data. Pearson's chi-square statistics was utilized to examine associations between LBP prevalence and subject characteristics. The level of significance for all statistical tests was set at $p<0.05$.

\section{I- Study population:}

The total number of working physiotherapists in governmental hospitals in Fayoum governate was 147 therapists distributed over 8 hospitals. One hundred and twelve physiotherapists participated in this study; that represent $76.19 \%$ from the target population.

\section{- Physical characteristics of the study group:}

Subjects mean $( \pm \mathrm{SD})$ age and BMI were $32.41 \pm$ 6.79 years and $25.81 \pm 2.52 \mathrm{~kg} / \mathrm{m}^{2}$ respectively as shown in (Table 1).
Table (1): Descriptive statistics for the mean age and BMI of the study group.

\begin{tabular}{lcccc}
\hline & $\mathrm{X} \pm \mathrm{SD}$ & Minimum & Maximum & Range \\
\hline Age (years) & $32.41 \pm 6.79$ & 25 & 59 & 34 \\
BMI $\left(\mathrm{kg} / \mathrm{m}^{2}\right)$ & $25.81 \pm 2.52$ & 20.03 & 29.73 & 9.71 \\
\hline
\end{tabular}

$X$ : Mean.

SD: Standard Deviation.

\section{- Foot posture:}

Table (2): The frequency distribution of foot posture of the study group.

\begin{tabular}{llllll}
\hline & \multicolumn{5}{c}{ Foot posture } \\
\cline { 2 - 6 } & Normal & Pronated & $\begin{array}{c}\text { Highly } \\
\text { pronated }\end{array}$ & Supinated & $\begin{array}{c}\text { Highly } \\
\text { supinated }\end{array}$ \\
\hline Frequency & 64 & 31 & 11 & 3 & 3 \\
N (\%) & $(57.14 \%)$ & $(27.67 \%)$ & $(9.82 \%)$ & $(2.67 \%)$ & $(2.67 \%)$ \\
\hline
\end{tabular}

\section{II- Prevalence of $L B P$ :}

- Lifetime prevalence, twelve-month prevalence and point prevalence:

Table (3): Lifetime prevalence, twelve-month prevalence and point prevalence of LBP in the study group.

\begin{tabular}{|c|c|c|c|c|c|c|}
\hline \multirow{2}{*}{ LBP } & \multicolumn{2}{|c|}{$\begin{array}{l}\text { Lifetime prevalence } \\
\text { (over their life time) }\end{array}$} & \multicolumn{2}{|c|}{$\begin{array}{l}\text { Twelve-month prevalence } \\
\text { (within the last twelve months) }\end{array}$} & \multicolumn{2}{|c|}{$\begin{array}{c}\text { Point prevalence } \\
\text { (the time of data collection) }\end{array}$} \\
\hline & $\begin{array}{l}\text { Frequency } \\
\quad \mathrm{N}(\%)\end{array}$ & $95 \% \mathrm{CI}$ & $\begin{array}{l}\text { Frequency } \\
\quad \mathrm{N}(\%)\end{array}$ & $95 \% \mathrm{CI}$ & $\begin{array}{l}\text { Frequency } \\
\quad \mathrm{N}(\%)\end{array}$ & $95 \% \mathrm{CI}$ \\
\hline WRLBP & $68(60.71 \%)$ & $51.45-69.25 \%$ & $59(52.67 \%)$ & $43.49-61.68 \%$ & $53(47.32 \%)$ & $38.31-56.5 \%$ \\
\hline Non-WRLBP & $25(22.32 \%)$ & $15.6-30.87 \%$ & $25(22.32 \%)$ & $15.6-30.87 \%$ & $25(22.32 \%)$ & $15.6-30.87 \%$ \\
\hline No LBP & $19(16.96 \%)$ & $11.13-24.98 \%$ & $28(25 \%)$ & $17.9-33.75 \%$ & $34(30.35 \%)$ & $22.61-39.4 \%$ \\
\hline Total & $112(100 \%)$ & & $112(100 \%)$ & & $112(100 \%)$ & \\
\hline
\end{tabular}

IV-Association between foot posture and LBP:

Table (4): The frequency distribution of LBP with different foot posture of the study group.

\begin{tabular}{llllll}
\hline & \multicolumn{5}{c}{ Foot posture } \\
\cline { 2 - 6 } & Normal & Pronated & $\begin{array}{c}\text { Highly } \\
\text { pronated }\end{array}$ & Supinated & $\begin{array}{c}\text { Highly } \\
\text { supinated }\end{array}$ \\
\hline WRLBP & $36(56 \%)$ & $17(55 \%)$ & $10(91 \%)$ & $3(100 \%)$ & $2(67 \%)$ \\
Non-WRLBP & $14(22 \%)$ & $10(32 \%)$ & $1(9 \%)$ & $0(0 \%)$ & $0(0 \%)$ \\
No LBP & $14(22 \%)$ & $4(13 \%)$ & $0(0 \%)$ & $0(0 \%)$ & $1(33 \%)$ \\
Total N (\%) & $64(57.14 \%)$ & $31(27.67 \%)$ & $11(9.82 \%)$ & $3(2.67 \%)$ & $3(2.67 \%)$ \\
$\chi 2$ value & & 10.45 & & \\
$p$-value & & 0.23 & NS & \\
Sig. & & & NS: Non Significant.
\end{tabular}

Table (5): The frequency distribution of WRLBP with different gender of the study group.

\begin{tabular}{|c|c|c|}
\hline & \multicolumn{2}{|c|}{ Gender } \\
\hline & Females & Males \\
\hline WRLBP & $34(54.83 \%)$ & $34(68 \%)$ \\
\hline Total N (\%) & $62(62 \%)$ & $50(45 \%)$ \\
\hline$\chi 2$ value & \multicolumn{2}{|c|}{2.01} \\
\hline$p$-value & \multicolumn{2}{|c|}{0.15} \\
\hline Sig. & \multicolumn{2}{|c|}{ NS } \\
\hline
\end{tabular}

$\overline{\chi^{2}}$ : Chi squared value. $p$-value: Probability value. NS: Non Significant.
Table (6): The frequency distribution of WRLBP with different BMI of the study group.

\begin{tabular}{lcc}
\hline & \multicolumn{2}{c}{ BMI } \\
\cline { 2 - 3 } & $20-24.9 \mathrm{~kg} / \mathrm{m}^{2}$ & $25-29.9 \mathrm{~kg} / \mathrm{m}^{2}$ \\
\hline WRLBP & $26(74.28 \%)$ & $42(54.54 \%)$ \\
Total N (\%) & $35(31.25 \%)$ & $77(68.75 \%)$ \\
$\chi 2$ value & & 3.93 \\
$p$-value & \multicolumn{2}{c}{0.04} \\
Sig. & \multicolumn{2}{c}{$\mathrm{S}$} \\
\hline$\chi^{2}:$ Chi squared value. & $p$-value: Probability value. S: Significant.
\end{tabular}


Table (7): The frequency distribution of WRLBP with different age of the study group.

\begin{tabular}{llcc}
\hline & \multicolumn{3}{c}{ Age group } \\
\cline { 2 - 4 } & $25-34$ years & $25-44$ years & $45-60$ years \\
\hline WRLBP & $50(61.73 \%)$ & $14(60.87 \%)$ & $4(50 \%)$ \\
Total N $(\%)$ & $81(72 \%)$ & $23(21 \%)$ & $8(7 \%)$ \\
$X$ value & & 0.42 & \\
$p$-value & & 0.81 & \\
Sig. & & NS & \\
\hline
\end{tabular}

$\mathrm{X}^{2}$ : Chi squared value. $p$-value: Probability value. NS: Non Significant.

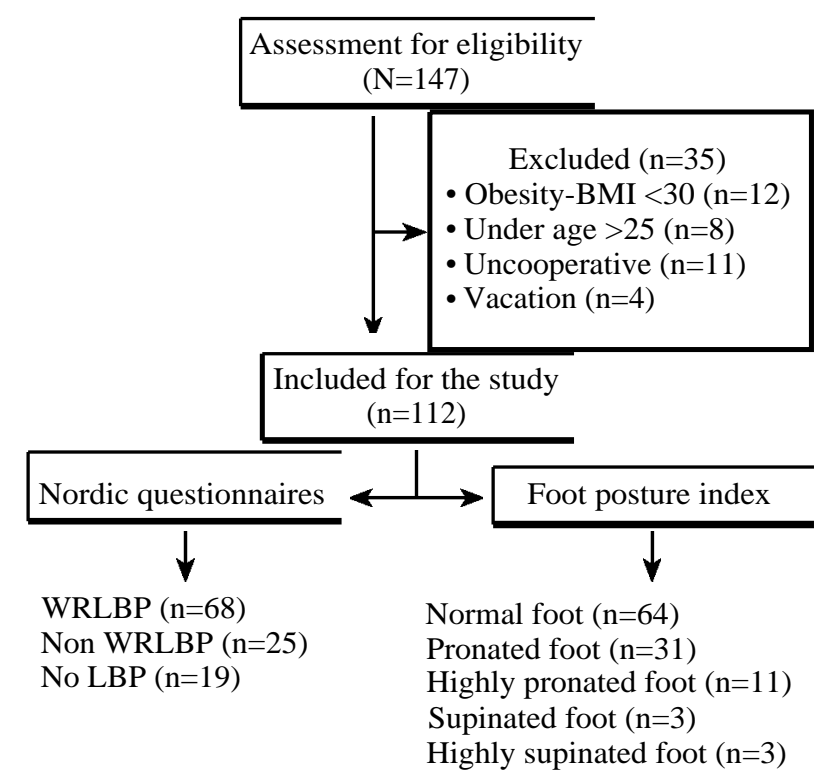

Fig. (7): Flow chart of the study.

\section{Discussion}

This study is a survey study aiming to find out the prevalence of work related low back pain among physical therapists in governmental hospitals fayoum-Egypt, including lifetime, twelve-month and point prevalence, as well as correlation of WRLBP to age, gender and BMI.

Concerning lifetime prevalence; the current study identified lifetime prevalence of WRLBP as $60.71 \%$, while lifetime prevalence of LBP among P. Ts was $29 \%$ in the USA [20] and $49.2 \%$ in Edmonton-Canada [21]. Lifetime prevalence of LBP was $70 \%$ among P. Ts in Kuwait [22]. While the United Kingdom (UK) P. Ts have reported a $48 \%$ lifetime prevalence of LBP [23].

Twelve-month prevalence the current study identified twelve-month prevalence of WRLBP as $52.67 \%$, while twelve-month prevalence of LBP among the American P. Ts was 45\% [24] and the Irish with $49 \%$ prevalence [25].

The current study point prevalence WRLBP; was $47.32 \%$, this was higher than UK's P. Ts which was $14 \%$ point prevalence [26], and lower than the Kuwaitian P. Ts which was $57 \%$ point prevalence [22].

Gender relation to WRLBP, the current study reported that the WRLBP was present in 34 $(54.83 \%)$ of female subjects and in $34(68 \%)$ of male subjects. There was no statistically significant association between WRLBP and gender, that is agree with an American study reported that, there is no effect of gender on LBP [20].

BMI and WRLBP prevalence among the current sampled P. Ts population, we have reported that the WRLBP was present in $74.28 \%$ of subjects with BMI of $20-24.9 \mathrm{~kg} / \mathrm{m}^{2}$ and in $54.54 \%$ of subjects with BMI of $25-29.9 \mathrm{~kg} / \mathrm{m}^{2}$. There was a statistically significant association between WRLBP and BMI. Results of the current study are in disagreement with [27] as their study have reported that there was no association between body weight or BMI and the occurrence of LBP within the population of industrial setting employees.

Age relation to WRLBP, the current study findings reported that the WRLBP was present in $61.73 \%$ of subjects with age of $25-34$ years, in $60.87 \%$ of subjects with age of $35-44$ years and in $50 \%$ of subjects with age of 45-60 years. There was no statistically significant association between WRLBP and age similar results were found by Shehab et al., (2003) [22] reported that in Kuwaitian P.Ts population most prevalent age group was (2630 years) with $80.7 \%$ prevalence, seconded by the (41-45 years) group with $76.1 \%$, while the oldest age group (above 55 years) had 50\% prevalence, while is in disagreement with systematic review of LBP prevalences in the general population of the African nations Morris et al., (2016) [28], which have demonstrated a linear trend with age by a gradual increase of LBP prevalence, of $11 \%$ in individuals aged (29 years or under) then $14 \%$ for (30-34 years) age group, to continue rising to reach $19 \%$ in those aged (50 years or more).

Foot posture, $57.14 \%$ had normal foot posture, $27.67 \%$ pronated foot, $9.82 \%$ highly pronated foot, $2.67 \%$ supinated foot and $2.67 \%$ had highly supinated foot. The association between foot posture and LBP, which the WRLBP was present in 56\% of subjects with normal foot posture, $55 \%$ of subjects with pronated foot posture, $91 \%$ of subjects with highly pronated foot posture, $100 \%$ of subjects with supinated foot posture and $67 \%$ of subjects with highly supinated foot posture. There was no statistically significant association between LBP and foot posture. 
Our results disagree with a large retrospective study of military recruits reported that those with moderate or severe pes planus (determined by clinical observation) were almost twice as likely to report a history of intermittent low back pain [29]. In contrast, two smaller clinical studies using more objective measurements of foot posture found no such association $[30,31]$, and a population-based study reported that those with low back pain were more likely to have a cavus (highly arched or supinated) foot posture [32]

Ogon et al., (1999) [33] indirectly measured shock forces transferred to the lumbar spine associated with running, using accelerometers attached to the skin at L3 level in subjects with varying heights of the medial longitudinal arch. Surprisingly, they detected less shock forces in those with higher medial longitudinal arches in their feet. This indicated that more supinated feet may be capable of more shock absorption. Therefore, pronated feet may afford less shock absorption to the lumbar spine, which would be consistent with the notion that foot pronation would be a risk factor for LBP.

Castro-Méndez et al., (2013) [34] in the sample studied, the use of custom-made foot orthoses to control foot pronation had a short-term effect in reduction of perceived low back pain. If subtalar joint hyperpronation plays a fundamental role in the pathomechanics of lower limb, and this can facilitate the development of low back pain, then controlling the abnormal mobility of subtalar joint by means of foot orthoses should improve this symptom.

Pinto et al., (2008) [35] measured the effect of increasing subtalar pronation on pelvic posture using reflective markers on the lower limbs and pelvis and a computerized 3-dimensional motion analysis system. They found that the bilateral and unilateral conditions caused increases of pelvic anteversion and the unilateral condition led to lateral pelvic tilt. These results show that the presence of excessive calcaneal eversion at the foot-ankle complex may be considered as a contributing factor for the production of pelvic misalignments during the maintenance of standing position. Thus, the position of the calcaneus should be taken into account, associated with other clinically relevant factors, when assessing pelvic posture in subjects with lumbopelvic disorders related to postural problems.

Khamis and Yizhar, (2007) [11] found results support the existence of a kinematic chain in healthy subjects, where hyperpronation can lead to an immediate shank and thigh internal rotation and change in pelvic position. This interaction was evaluated while standing. Furthermore, an asymmetrical change in foot alignment should be considered since it may cause asymmetrical pelvic change and pelvic torsion, which might enhance symptoms or dysfunction. The clinical implication of this study advocates that when addressing pelvic and lower back dysfunction, alignment of the foot should be considered as a contributing factor.

Betsch et al., (2011) [36] was found the results of study support the existence of a kinematic chain, where changes of foot position also led to significant alterations of the pelvic position. Whether these changes could lead to long-term pathologic alterations still needs to be evaluated. Positive and negative heel heights as well as an increase of the outer margin of the platform led to significant changes of the pelvic tilt. However, in our setting, no correlation between foot position and spinal posture changes was found.

While the results of the current study agree with Menz et al., (201 3) [37] who reported that although the presence of low back pain, aching or stiffness on most days. Neither foot posture (cavus or planus) nor asymmetry in foot posture or foot function showed an association with low back pain.

Also Duval et al., (2010) [38] had found Foot pronation and supination did not have a significant relationship with pelvic tilt or lumbar lordosis. Internally rotating the legs caused the pelvis to tilt anteriorly and externally rotating the legs caused the pelvis to tilt posteriorly. Also there was no relationship between leg rotation and lumbar lordosis. Since the effects of pelvic tilt on the lumbar spine were only noticeable when pelvic tilt was exaggerated beyond values seen this study it seems unlikely that there is a link between induced foot pronation and an increase in lumbar lordosis.

\section{Conclusion:}

Based on the scope and findings of this study, it could be concluded that work related LBP with different foot postures will be high risk among physical therapists working in governmental hospitals in Fayoum-Egypt. There was no statistically significant association between LBP and foot postures, however there was a statistically significant (+ve) association between WRLBP and BMI. There was a high prevalence of WRLBP among physical therapists working in governmental hospitals in Fayoum-Egypt. 


\section{References}

1- LONEY P.L. and STRATFORD P.W.: The prevalence of low back pain in adults: A methodological review of the literature. Physical Therapy, 79: 384-96, 1999.

2- ANDERSSON G.B.: Epidemiological features of chronic low-back pain. The lancet, 354 (9178): 581-5, 1999.

3- KENT P.M. and KEATING J.L.: The epidemiology of low back pain in primary care. Chiropractic \& osteopathy, 13 (1): 13, 2005.

4- HOLDER N.L., CLARK H.A., DiBLASIO J.M. and HUGHES C.L.: Cause, prevalence, and response to occupational musculoskeletal injuries reported by physical therapists and physical therapist assistants. Physical therapy, 79 (7): 642, 1999.

5- CIBULKA M.T., SINACORE D.R., CROMER G.S. and DELITTO A.: Unilateral hip rotation range of motion asymmetry in patients with sacroiliac joint regional pain. Spine, 23 (9): 1009-15, 1998.

6- ROTHBART B.A. and ESTABROOK L.: Excessive pronation: A major biomechanical determinant in the development of chondromalacia and pelvic lists. Journal of manipulative and physiological therapeutics, 11 (5): 3739, 1998.

7- BIRD A.R.: Foot function and low back pain. The Foot, 9 (4): 175-80, 1999.

8- BOTTE R.R.: An interpretation of the pronation syndrome and foot types of patients, 1981.

9- MICHAUD T.C.: Foot orthoses and other forms of conservative foot care. Williams \& Wilkins. With low back pain. Journal of the American Podiatry Association, 71 (5): 243, 1997.

10- TIBERIO D.: Pathomechanics of structural foot deformities. Physical Therapy, 68 (12): 1840-9, 1988.

11-KHAMIS S. and YIZHAR Z.: Effect of feet hyperpronation on pelvic alignment in a standing position. Gait \& posture, 25 (1): 127-34, 2007.

12- LEVINE D. and WHITTLE M.W.: The effects of pelvic movement on lumbar lordosis in the standing position. Journal of Orthopaedic \& Sports Physical Therapy, 24 (3): 130-5, 1996.

13- LEGAYE J., DUVAL-BEAUPERE G., HECQUET J. and MARTY C.: Pelvic incidence: A fundamental pelvic parameter for three-dimensional regulation of spinal sagittal curves. European Spine Journal, 7: 99-103, 1998.

14- GURNEY B.: Leg length discrepancy. Gait \& posture, 15 (2): 195-206, 2002.

15- FRANCO A.H.: Pes cavus and pes planus. Physical Therapy, 67: 688-94, 1987.

16- HERTEL J., GAY M.R. and DENEGAR C.R.: Differences in postural control during single leg stance among healthy individuals with different foot types. Journal of athletic training, 37 (2): 129-32, 2002.

17- NAWOCZENSKI D.A. and LUDEWIG P.M.: Electromyographic effects of foot orthotics on selected lower extremity muscles during running. Archives of physical medicine and rehabilitation, 80 (5): 540-4, 1999.
18- TOMARO J. and BURDETT R.C.: The effects of foot orthotics on the EMG activity of selected leg muscles during gait. Journal of Orthopaedic \& Sports Physical Therapy, 18 (4): 532-6, 1993.

19- REDMOND A.C.: The Foot Posture Index: User guide and manual. Retrieved September, 30: 2008, 2005.

20- MOLUMPHY, MARGARET, BOBBI UNGER, GAIL M. JENSEN and ROSALIE B. LOPOPOLO: Incidence of work-related low back pain in physical therapists', Physical therapy, 65: 482-6, 1985.

21- MIERZEJEWSKI M. and KUMAR S.: Prevalence of low back pain among physical therapists in Edmonton, Canada. Disability and Rehabilitation, 19: 309-17, 1997.

22- SHEHAB D., AL-JARALLAH K., MOUSSA M.A. and ADHAM N.: Prevalence of low back pain among physical therapists in Kuwait. Medical Principles and Practice, 12: 224-30, 2003.

23- GLOVER W., McGREGOR A., SULLIVAN C. and HAGUE J.: Work-related musculoskeletal disorders affecting members of the Chartered Society of Physiotherapy. Physiotherapy, 91 (3): 138-47, 2005.

24- BORK B.E., COOK T.M., ROSECRANCE J.C., ENGELHARDT K.A., THOMASON M.E.J., WAUFORD I.J. and WORLEY R.K.: Work-related musculoskeletal disorders among physical therapists. Physical therapy, 76: 827-35, 1996.

25- HOGAN D., O'SULLIVAN L., NOLAN S. and GREINER B.: Are Irish therapists at heightened risk for low back pain? Occupational Medicine, kqw020 accepted for publication, 2016

26- SCHOLEY M. and HAIR M.: Back pain in physiotherapists involved in back care education. Ergonomics, 32: 17990, 1989.

27- LEE P., HELEWA A., GOLDSMITH C.H., SMYTHE H.A. and STITT L.W.: Low back pain: Prevalence and risk factors in an industrial setting. The Journal of rheumatology, 28: 346-51, 2001.

28- MORRIS L., DANIEL S.K. and LOUW Q.: The prevalence of low back pain in Africa. Manual Therapy, 25: e122e123, 2016.

29- KOSASHVILI Y., FRIDMAN T., BACKSTEIN D., SAFIR O. and ZIV Y.B.: The correlation between pes planus and anterior knee or intermittent low back pain. Foot \& ankle international, 29 (9): 910-3, 2008.

30- BRANTINGHAM J.W., GILBERT J.L., SHAIK J. and GLOBE G.: Sagittal plane blockage of the foot, ankle and hallux and foot alignment-prevalence and association with low back pain. Journal of Chiropractic Medicine, 5 (4): 123-7, 2006.

31- BRANTINGHAM J.W., ADAMS K.J., COOLEY J.R., GLOBE D. and GLOBE G.: A single-blind pilot study to determine risk and association between navicular drop, calcaneal eversion, and low back pain. Journal of Manipulative \& Physiological Therapeutics, 30 (5): 380-5, 2007.

32- RONCARATI A. and McMULLEN W.: Correlates of low back pain in a general population sample: A multidisciplinary perspective. Journal of manipulative and physiological therapeutics, 11 (3): 158-64, 1988. 
33- OGON M., ALEKSIEV A.R., POPE M.H., WIMMER C. and SALTZMAN C.L.: Does arch height affect impact loading at the lower back level in running? Foot \& ankle international, 20 (4): 263-6, 1999.

34- CASTRO-MÉNDEZ A., MUNUERA P.V. and ALBORNOZ-CABELLO M.: The short-term effect of custommade foot orthoses in subjects with excessive foot pronation and lower back pain: A randomized, double-blinded, clinical trial. Prosthetics and orthotics international, 37 (5): 384-90, 2013.

35- PINTO R.Z., SOUZA T.R., TREDE R.G., KIRKWOOD R.N., FIGUEIREDO E.M. and FONSECA S.T.: Bilateral and unilateral increases in calcaneal eversion affect pelvic alignment in standing position. Manual therapy, 13 (6): 513-9, 2008.

36- BETSCH M., SCHNEPPENDAHL J., DOR L., JUNGBLUTH P., GRASSMANN J.P., WINDOLF J. and WILD M.: Influence of foot positions on the spine and pelvis. Arthritis care \& research, 63 (12): 1758-65, 2011.

37- MENZ H.B., DUFOUR A.B., RISKOWSKI J.L., HILLSTROM H.J. and HANNAN M.T.: Foot posture, foot function and low back pain: The Framingham Foot Study. Rheumatology, 52 (12): 2275-82, 2013.

38- DUVAL K., LAM T. and SANDERSON D.: The mechanical relationship between the rearfoot, pelvis and lowback. Gait \& posture, 32 (4): 637-40, 2010.

\section{Appendix 1}

$+1+$

\section{Questionnaire for prevalence of low back pain}

* Please answer by putting a mark in or shading the appropriate box.

* By answering this questionnaire, you agree for the scientific publication of the provided answers.

* Some questions allow you to mark more than one box.

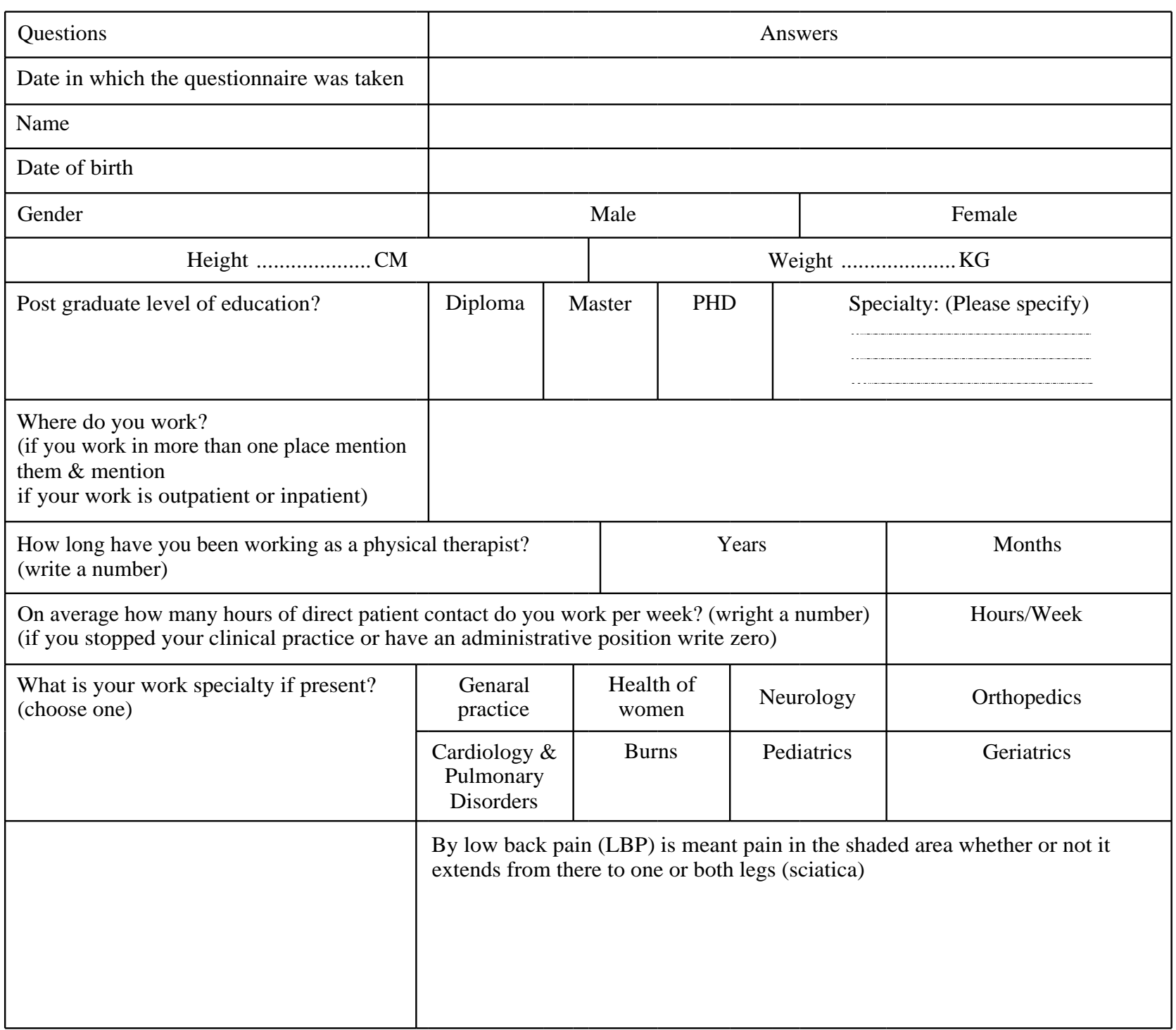




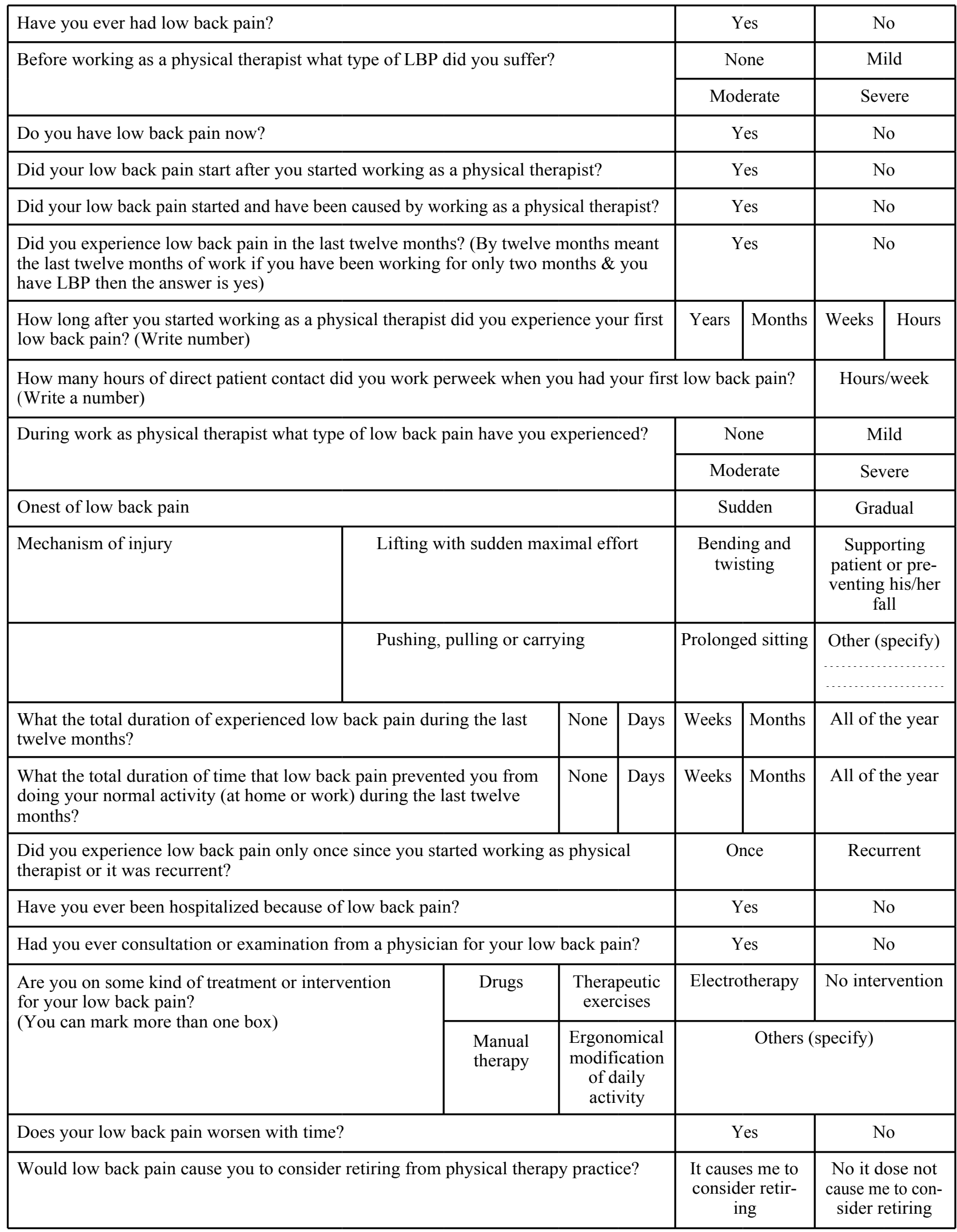

Your current low back pain level is (mark the diagram or write a number)

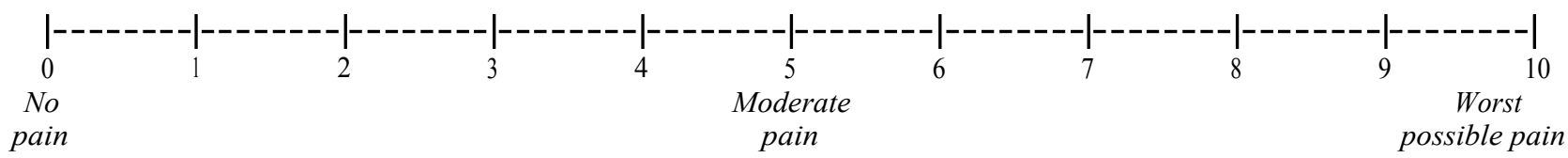




\section{Appendix 2}

$+1+$

Foot Posture Index Datasheet

\begin{tabular}{|c|c|c|c|c|c|c|c|}
\hline \multirow{2}{*}{ FACTOR } & \multirow{2}{*}{ PLANE } & \multicolumn{2}{|c|}{$\begin{array}{l}\text { SCORE } 1 \\
\text { Date } \\
\text { Comment }\end{array}$} & \multicolumn{2}{|c|}{$\begin{array}{l}\text { SCORE } 2 \\
\text { Date } \\
\text { Comment }\end{array}$} & \multicolumn{2}{|c|}{$\begin{array}{l}\text { SCORE } 3 \\
\text { Date } \\
\text { Comment }\end{array}$} \\
\hline & & $\begin{array}{l}\text { Left } \\
(-2 \text { to } \\
+2)\end{array}$ & $\begin{array}{l}\text { Right } \\
(-2 \text { to } \\
+2)\end{array}$ & $\begin{array}{l}\text { Left } \\
(-2 \text { to } \\
+2)\end{array}$ & $\begin{array}{l}\text { Right } \\
(-2 \text { to } \\
+2)\end{array}$ & $\begin{array}{l}\text { Left } \\
(-2 \text { to } \\
+2)\end{array}$ & $\begin{array}{l}\text { Right } \\
(-2 \text { to } \\
+2)\end{array}$ \\
\hline Talar head palpation & Transverse & & & & & & \\
\hline $\begin{array}{l}\text { Curves above and below lateral } \\
\text { malleoli }\end{array}$ & $\begin{array}{c}\text { Frontal/ } \\
\text { trans }\end{array}$ & & & & & & \\
\hline Inversion/eversion of the calxaneus & Frontal & & & & & & \\
\hline Bulge in the region of the TNJ & Transverse & & & & & & \\
\hline $\begin{array}{l}\text { Congruence of the medial longitudinal } \\
\text { arch }\end{array}$ & Sagittal & & & & & & \\
\hline $\begin{array}{l}\text { Abd/adduction of forefoot on rearfoot } \\
\text { (too-many-toes) }\end{array}$ & Transverse & & & & & & \\
\hline Total & & & & & & & \\
\hline
\end{tabular}

Reference values

Normal $=0$ to +5

Pronated $=+6$ to +9 , Highly pronated $10+$

Supinated $=-1$ to -4 , Highly supinated -5 to -12 v Anthony Redmond 1998

(May be copied for clinical use, and adapted with the permission of the copyright holder) www.leeds.ac.uk/medicine/FASTER/FPI/

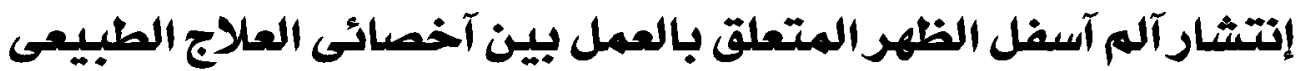

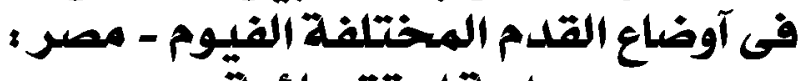 دراسلة إستقصائية}

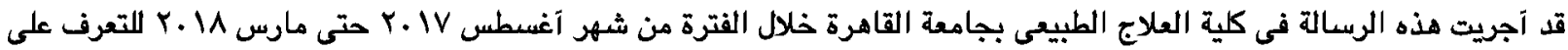

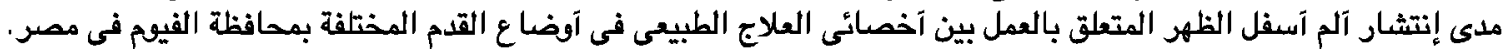

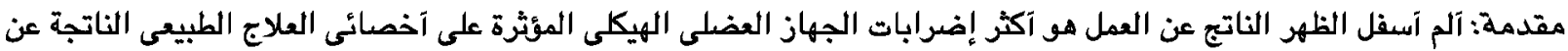

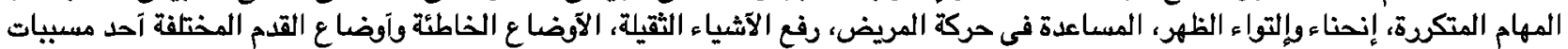
آلم آسفل الظهر.

الهدف: من هذه الدراسة هو التعرف على مدى إنتشار آلم آسفل الظهر المتعلق بالعمل بين آخصائى العلاج الطبيعى في آوضاع القدم المختلفة بالفيوم في مصن هذه

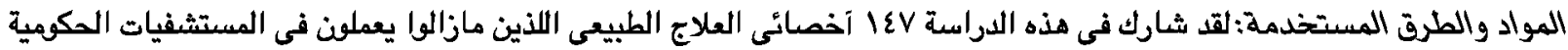

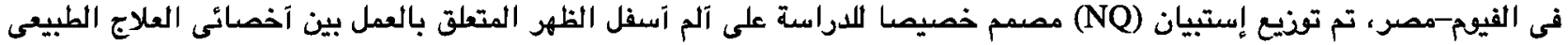

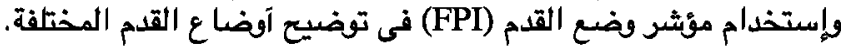

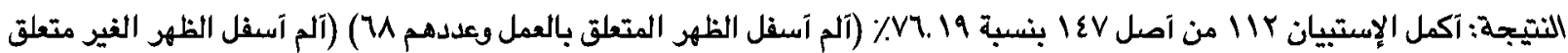

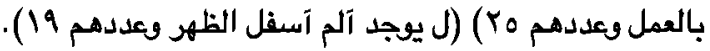

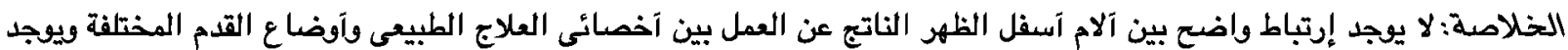

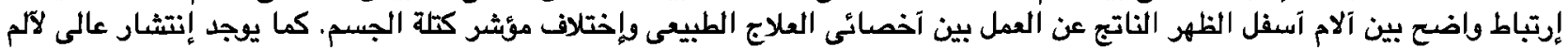

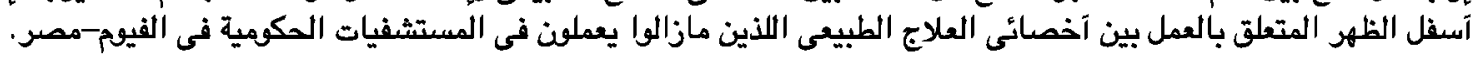

